Proceedings

\title{
Effect of Acceptor and Donor Substituents in the ortho, meta, and para Positions in the Nitrobenzene Molecule on the Reaction of Interaction with Ethylene $^{+}$
}

\author{
Yuri V. Minasyan, Anastasia I. Degtyarenko, Karina D. Kosmacheva, Sergei D. Plekhovich * and \\ Sergei V. Zelentsov \\ NNGU. Chemical Department, Nizhnii Novgorod State University, Nizhnii Novgorod 603950, Russia; \\ yram6@rambler.ru (Y.V.M.); Anastasiadegtyarenko@mail.ru (A.I.D.); karina.kosmacheva@mail.ru (K.D.K.); \\ senypl@mail.ru (S.V.Z.) \\ * Correspondence: zelentsov@chem.unn.ru \\ † Presented at the 22nd International Electronic Conference on Synthetic Organic Chemistry, 15 November- \\ 15 December 2018; Available Online: https://sciforum.net/conference/ecsoc-22.
}

Published: 14 November 2018

\begin{abstract}
The uB3LYP/6-311g++(d,p) method in the gas phase was used to simulate the reaction of ethylene with ortho, meta, para methylnitrobenzene, chloronitrobenzene, $\left(\mathrm{CCl}_{3}\right) \mathrm{PhNO}_{2},\left(\mathrm{CF}_{3}\right) \mathrm{PhNO}_{2}$ in the $\mathrm{T}_{1}$ state, as well as determining the influence of the position of donor and acceptor substituents in the benzene ring on the activation energy of the reaction under study. It is established that during the reaction ethylene oxide and nitroso compound are formed.
\end{abstract}

Keywords: uB3LYP; reaction mechanism; the triplet state; transitional state, nitrobenzene

\section{Introduction}

Ethylene oxide is one of the target oxidation products of the olefin. It is widely used as a fumigant and as an intermediate in the synthesis of solvents, lubricants, hydraulic liquids and emulsifiers. Therefore, the researches in the field of the olefin oxidations to oxygenated compounds are relevant. Especially important is the development of new methods of low-temperature oxidation. An interesting group of the photochemical oxidants of olefins are the aromatic nitro compounds. Buchi [1] reported that under the irradiation of a mixture of nitrobenzene and 2-methyl-2-butene by UV light, a complex mixture of products with low yields forms. In the study of the qualitative composition of the reaction products, it has become clear that the ethylene bond is susceptible to the nitrobenzene-induced photochemical oxidation. These authors suggested that cyclic compounds are formed as intermediates. The proof of the hypothesis is given in [2].

The aim of our work was a quantum chemical simulation of the interaction of ethylene with methyl nitrobenzene, 3-chlorine nitrobenzene, 3-fluorine nitrobenzene and chloronitrobenzene in the $\mathrm{T}_{1}$ state, as well as to reveal the influence of the position of donor and acceptor substituents in the benzene ring on the activation energy of the reaction under study.

\section{Experimental Technique}

Quantum-chemical modeling of the systems under study was performed using the Gaussian 03 program, DFT method with uB3LYP/6-311g ++ $(\mathrm{d}, \mathrm{p})$ basic set. The selection of the method and basis is based on the works [3,4]. To achieve this goal, they optimized the geometry of the systems under study, calculated transition states and determined their geometrical parameters. The activation energy is determined, taking into account the energy of zero point. 


\section{Results and Its Discussion}

The mechanism of the reaction of the interaction of aromatic nitro compounds with ethylene is similar to the mechanism discussed in [5]. At the first stage (Figure 1), UV light is exposed to the aromatic nitro compound with its transition to the excited $S_{1}$ state, then it undergoes ISC (intersystem crossing) with the transition to the $\mathrm{T}_{1}$ state. Such a transition becomes possible due to the close location of the $S_{1}$ and $T_{1}$ levels in aromatic nitro compounds. For example, the energy difference between the $S_{1}$ and Tn levels in nitronaphthalene is $0.1-0.2 \mathrm{eV}[6]$.
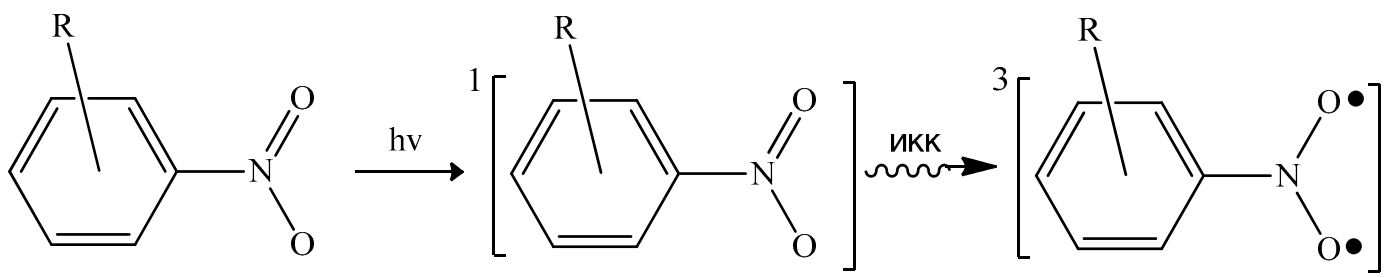

Figure 1. The first stage of reaction

The next reaction is the addition of NA in the $\mathrm{T}_{1}$ state on the olefin double bond (Figure 2).

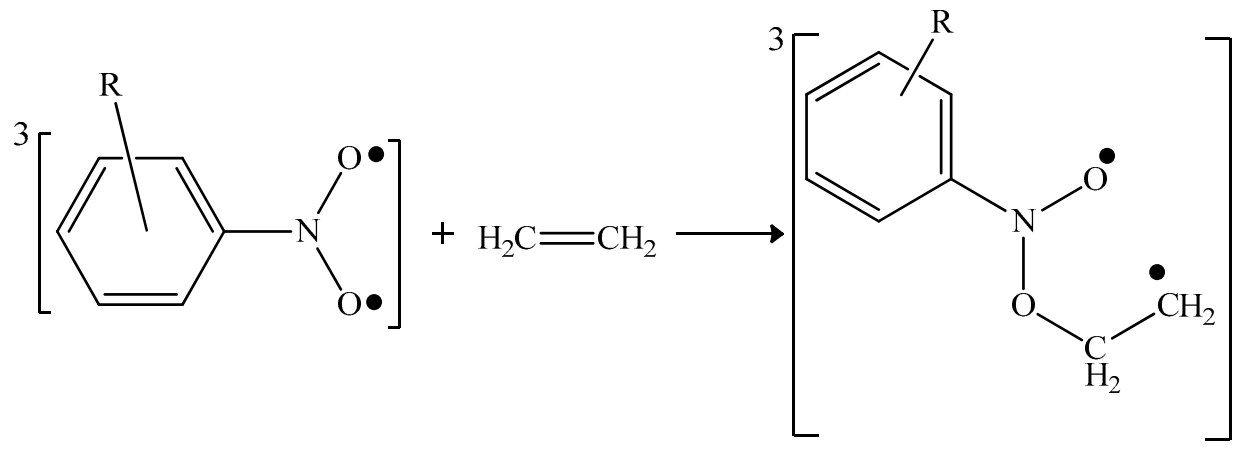

Figure 2. The second stage of reaction

In the third reaction, the resulting adduct is decomposed into oxide and nitrosomethane, which is in the triplet state (Figure 3).

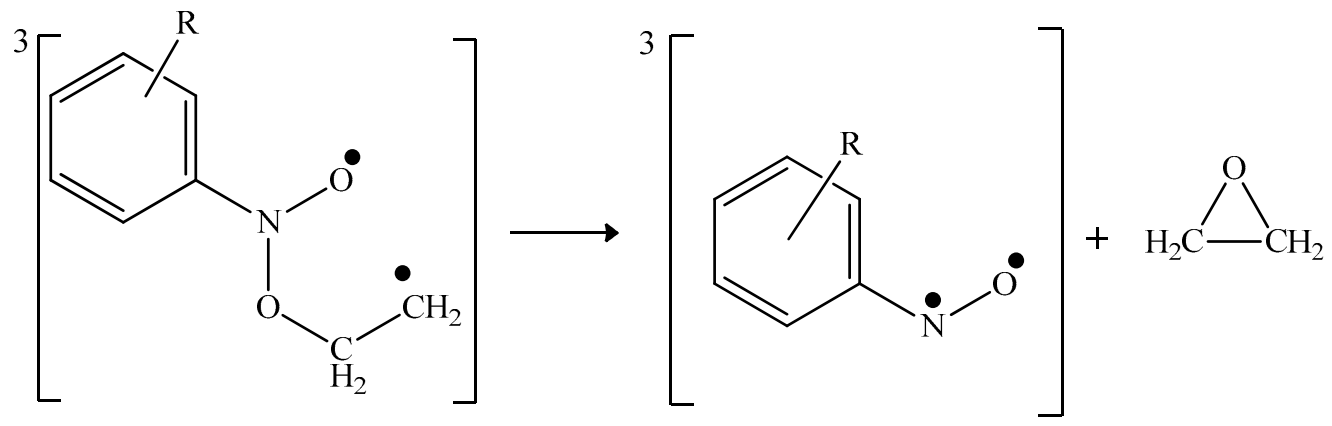

Figure 3. The third stage of reaction.

Table 1 presents the geometry of the transition state of the first reaction stage. For the first stage of the reaction, the key parameters are: The $\mathrm{C}-\mathrm{O}$ bond distance, angle of attack, and pyramidal angle. Based on the obtained calculations, it is possible to identify the following patterns:

- With an increase in the length of the $\mathrm{C}-\mathrm{O}$ bond in the transition state, the activation energy decreases:

- With an increase in the angle of attack, an increase in the activation energy occurs, 
where $\mathrm{r}(\mathrm{C}-\mathrm{O})$-is the $\mathrm{C}-\mathrm{O}$ bond length, ${ }^{*} \phi_{\text {attack }}-$ is the angle of attack, ${ }^{* *} \phi_{\text {pyramidal }}-$ is the pyramidal angle, Ea-is the activation energy, $\Delta \mathrm{rH}-$ is the reaction enthalpy. $\mathrm{Ea}_{\mathrm{a}} \mathrm{kkal} / \mathrm{mol}, \Delta_{\mathrm{r}} \mathrm{H}, \mathrm{kkal} / \mathrm{mol}$.

Table 1. Geometry of the transition state and reaction kinetics 1.

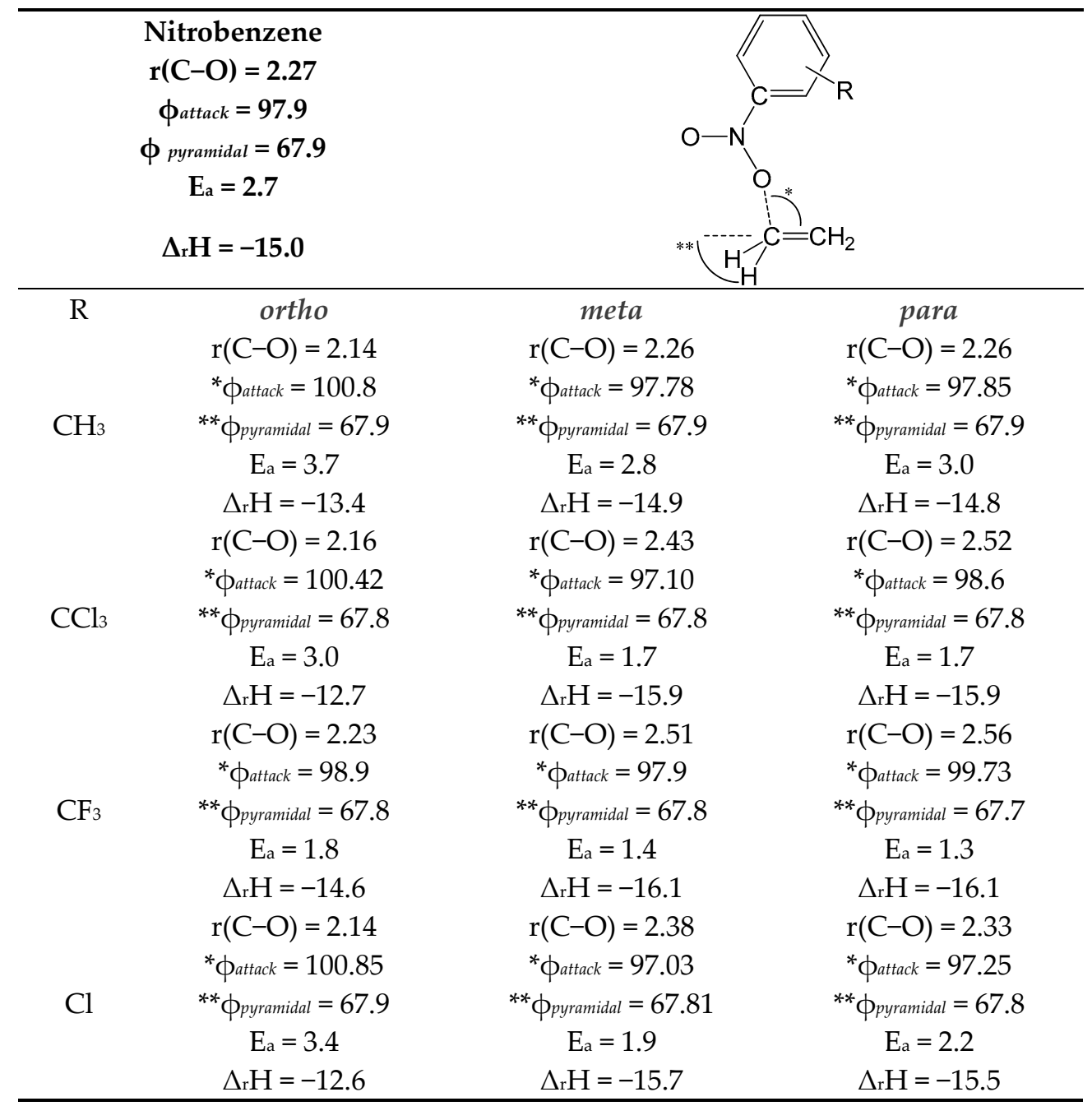

It is also clear from the results obtained that with an increase in the activation energy, the enthalpy of the reaction increases.

When considering the second stage of the reaction Table 2, we single out such parameters as the $\mathrm{N}-\mathrm{O}$ bond distance, the difference in charges on the $\mathrm{N}$ and $\mathrm{C}$ atoms.

Compared with the first stage, the length of the $\mathrm{N}-\mathrm{O}$ bond does not change when the position of the substituent changes. However, there is a significant increase in the difference in the magnitudes of the charges on the $\mathrm{N}$ and $\mathrm{C}$ atoms located in the reaction center. In the case where the substituent is at the ortho position, a decrease in the activation energy of decay is observed in comparison with the meta and para positions. 
Table 2. Geometry of the transition state and kinetics of the reaction 2.

\begin{tabular}{|c|c|c|c|}
\hline \multicolumn{2}{|c|}{ Nitrobenzene } & & \\
\hline \multicolumn{2}{|c|}{$\mathrm{r}(\mathrm{N}-\mathrm{O})=2.14$} & & \\
\hline \multicolumn{2}{|c|}{$\Delta \mu(\mathrm{N}-\mathrm{O})=0.082$} & & $R$ \\
\hline \multicolumn{2}{|c|}{$\Delta \mu(\mathrm{N}-\mathrm{C})=1.204$} & & \\
\hline \multicolumn{2}{|r|}{$E_{a}=13.5$} & & \\
\hline \multicolumn{2}{|c|}{$\Delta_{\mathrm{r}} \mathrm{H}=-24.0$} & & \\
\hline \multirow[t]{3}{*}{$\mathrm{R}$} & ortho & meta & para \\
\hline & $\mathrm{r}(\mathrm{N}-\mathrm{O})=2.14$ & $\mathrm{r}(\mathrm{N}-\mathrm{O})=1.87$ & $\mathrm{r}(\mathrm{N}-\mathrm{O})=1.88$ \\
\hline & $\Delta \mu(\mathrm{N}-\mathrm{O})=0.082$ & $\Delta \mu(\mathrm{N}-\mathrm{O})=0.08$ & $\Delta \mu(\mathrm{N}-\mathrm{O})=0.07$ \\
\hline \multirow[t]{5}{*}{$\mathrm{CH}_{3}$} & $\Delta \mu(\mathrm{N}-\mathrm{C})=1.204$ & $\Delta \mu(\mathrm{N}-\mathrm{C})=0.587$ & $\Delta \mu(\mathrm{N}-\mathrm{C})=0.307$ \\
\hline & $E_{a}=13.5$ & $\mathrm{E}_{\mathrm{a}}=14.9$ & $E_{a}=14.9$ \\
\hline & $\Delta_{\mathrm{r}} \mathrm{H}=-24.0$ & $\Delta_{\mathrm{r}} \mathrm{H}=-20.2$ & $\Delta_{\mathrm{r}} \mathrm{H}=-19.3$ \\
\hline & $\mathrm{r}(\mathrm{N}-\mathrm{O})=1.86$ & $\mathrm{r}(\mathrm{N}-\mathrm{O})=1.86$ & $\mathrm{r}(\mathrm{N}-\mathrm{O})=1.85$ \\
\hline & $\Delta \mu(\mathrm{N}-\mathrm{O})=0.299$ & $\Delta \mu(\mathrm{N}-\mathrm{O})=0.302$ & $\Delta \mu(\mathrm{N}-\mathrm{O})=0.203$ \\
\hline \multirow[t]{5}{*}{$\mathrm{CCl}_{3}$} & $\Delta \mu(\mathrm{N}-\mathrm{C})=0.404$ & $\Delta \mu(\mathrm{N}-\mathrm{C})=0.302$ & $\Delta \mu(\mathrm{N}-\mathrm{C})=0.095$ \\
\hline & $\mathrm{E}_{\mathrm{a}}=12.4$ & $\mathrm{E}_{\mathrm{a}}=14.9$ & $E_{a}=14.9$ \\
\hline & $\Delta_{\mathrm{r}} \mathrm{H}=-29.9$ & $\Delta_{\mathrm{r}} \mathrm{H}=-20.3$ & $\Delta_{\mathrm{r}} \mathrm{H}=-19.8$ \\
\hline & $\mathrm{r}(\mathrm{N}-\mathrm{O})=1.86$ & $\mathrm{r}(\mathrm{N}-\mathrm{O})=1.86$ & $\mathrm{r}(\mathrm{N}-\mathrm{O})=1.85$ \\
\hline & $\Delta \mu(\mathrm{N}-\mathrm{O})=0.195$ & $\Delta \mu(\mathrm{N}-\mathrm{O})=0.113$ & $\Delta \mu(\mathrm{N}-\mathrm{O})=0.141$ \\
\hline \multirow[t]{5}{*}{$\mathrm{CF}_{3}$} & $\Delta \mu(\mathrm{N}-\mathrm{C})=0.939$ & $\Delta \mu(\mathrm{N}-\mathrm{C})=0.548$ & $\Delta \mu(\mathrm{N}-\mathrm{C})=0.334$ \\
\hline & $\mathrm{E}_{\mathrm{a}}=12.9$ & $\mathrm{E}_{\mathrm{a}}=14.9$ & $\mathrm{E}_{\mathrm{a}}=14.9$ \\
\hline & $\Delta_{\mathrm{r}} \mathrm{H}=-26.1$ & $\Delta_{\mathrm{r}} \mathrm{H}=-20.3$ & $\Delta_{\mathrm{r}} \mathrm{H}=-19.9$ \\
\hline & $\mathrm{r}(\mathrm{N}-\mathrm{O})=1.87$ & $\mathrm{r}(\mathrm{N}-\mathrm{O})=1.86$ & $\mathrm{r}(\mathrm{N}-\mathrm{O})=1.87$ \\
\hline & $\Delta \mu(\mathrm{N}-\mathrm{O})=0.043$ & $\Delta \mu(\mathrm{N}-\mathrm{O})=0.096$ & $\Delta \mu(\mathrm{N}-\mathrm{O})=0.876$ \\
\hline \multirow[t]{3}{*}{$\mathrm{Cl}$} & $\Delta \mu(\mathrm{N}-\mathrm{C})=1.5$ & $\Delta \mu(\mathrm{N}-\mathrm{C})=0.575$ & $\Delta \mu(\mathrm{N}-\mathrm{C})=0.510$ \\
\hline & $\mathrm{E}_{\mathrm{a}}=12.4$ & $E_{a}=14.9$ & $E_{a}=14.9$ \\
\hline & $\Delta_{\mathrm{r}} \mathrm{H}=-26.2$ & $\Delta_{\mathrm{r}} \mathrm{H}=-20.2$ & $\Delta_{\mathrm{r}} \mathrm{H}=-19.9$ \\
\hline
\end{tabular}

where $\mathrm{r}(\mathrm{N}-\mathrm{O})$ is the $\mathrm{N}-\mathrm{O}$ bond length, $\Delta \mu(\mathrm{N}-\mathrm{O})$ is the difference in charge values on $\mathrm{N}$ and $\mathrm{O}$ atoms, $\Delta \mu(\mathrm{N}-\mathrm{C})$ is the difference in charge values on $\mathrm{N}$ and $\mathrm{C}_{\text {., }} \mathrm{E}_{\mathrm{a}}, \mathrm{kkal} / \mathrm{mol}, \Delta_{\mathrm{r}} \mathrm{H}, \mathrm{kkal} / \mathrm{mol}$.

\section{Conclusions}

The effect of acceptor and donor substituents in the ortho, meta, and para positions in the nitrobenzene molecule on the reaction of interaction with ethylene was determined:

(1) with an increase in the length of the $\mathrm{C}-\mathrm{O}$ bond in the transition state, the activation energy decreases.

(2) with an increase in the angle of attack, an increase in the activation energy occurs.

(3) with an increase in the activation energy, the enthalpy of the reaction increases.

(4) It was found that ethylene oxide and a nitroso compound are formed during the reaction.

Acknowledgments: This work was supported by project no. 4.5706.2017/BCh.

\section{References}

1. Buchi, G.; Ayer, D.E. Effect of Ultraviolet Light on Alkaline Solutions of Glucose and Certain Other Sugars. J. Am. Chem. Soc. 1956, 78, 689.

2. Charlton, J.L.; Liao, C.C.; de Mayo, P. Photochemical synthesis. The addition of aromatic nitro compounds to alkenes. J. Am. Chem. Soc. 1971, 93, 2463-2471. 
3. Mahadevan, D.; Periandy, S.; Ramalingam, S. Vibrational spectroscopy (FTIR and FTRaman) investigation using ab initio (HF) and DFT (B3LYP) calculations on the structure of 3-Bromo phenol. Spectrochim. Acta Part A: Mol. Biomol. Spectrosc. 2011, 78, 575-581.

4. Vogt, R.A.; Reichardt, C.; Crespo-Hernández, C.E. Excited-State Dynamics in Nitro-Naphthalene Derivatives: Intersystem Crossing to the Triplet Manifold in Hundreds of Femtoseconds. J. Phys. Chem. A 2013, 117, 65806588.

5. Gorner, H. Theoretical Investigation of the Directional Electron Transfer in 4-Aminonaphthalimide Compounds. J. Phys. Chem. A 2002, 106, 5989-5998.

6. Vogt, A.R.; Reichardt, C.; Crespo-Hernández, E. Role of intersystem crossing in the fluorescence quenching of 2-aminopurine 2'-deoxyriboside in solution. J. Photochem. Photobiol. Sci. 2013, 12, 1341-1350.

(C) 2018 by the authors. Licensee MDPI, Basel, Switzerland. This article is an open access article distributed under the terms and conditions of the Creative Commons Attribution (CC BY) license (http://creativecommons.org/licenses/by/4.0/). 